\title{
Relaciones entre periodismo y literatura: fusión sin confusión
}

\author{
Journalism and literature: fusion without confusion
}

\author{
Dr. Jorge A. Cortés Montalvo \\ Universidad Autónoma de \\ Chihuahua (UACH), México \\ jcortes@uach.mx

\section{Ddo. José Antonio García Pérez \\ Universidad Autónoma de \\ Chihuahua (UACH), México \\ jogarcía@uach.mx}

Recibido: 19 de abril de 2012

Aceptado: 30 de junio de 2012

\begin{abstract}
Resumen
Las relaciones diacrónicas y sincrónicas entre la cultura literaria y la cultura periodística describen un objeto de conocimiento que debe ser abordado desde una perspectiva interdisciplinaria, puesto que es un ámbito donde concurren las ciencias sociales, los medios de comunicación y el arte, así como en el caso particular que aquí se aborda, la literatura. Periodismo y Literatura, como disciplinas humanísticas, cada una con su propio pasado y presente van a la par con el cambio, por lo que están en continua evolución y transformación, y en su camino nos descubren los límites entre nuevas formas de expresión.
\end{abstract}

\begin{abstract}
The diachronic and synchronous relations between the literary culture and the journalistic culture describe a knowledge object that must be boarded from an interdisciplinary perspective, since it is a scope where concur social sciences, mass media and the art, as well as in the particular case that it is approached here, Literature. Journalism and Literature, like humanistic disciplines, each with their own one past and present go on a par with the change, reason why they are in continuous evolution and transformation, and in its way they discover the limits to us between new forms of expression.
\end{abstract}

Palabras Clave: Relaciones diacrónicas y sincrónicas, cultura literaria, cultura periodística, periodismo cultural, medios de comunicación, literatura

Key Words: Diachronic and synchronous relations, literary culture, journalistic, cultural journalism, mass media, literature. 


\section{Periodismo y literatura}

"Toda publicación que ve la luz pública con intervalos regulares se llama periódica. En el sentido vulgar, el periodismo se refiere a las publicaciones diarias de la mañana o de la noche"

(Martín Alonso Pedraz, 1975).

El autor del parágrafo que abre este escrito; filólogo, lexicógrafo, gramático, periodista y poeta español, es de la opinión de que el periodismo tiene una triple función: informar, orientar y deleitar (1) (Alonso, 1975, Pág. 476). Dicha tríada sigue vigente y fusionando la Literatura con el Periodismo.

Las aportaciones de estudiosos y críticos del periodismo cultural, coinciden en que la frontera entre ambas actividades humanísticas, tal vez sea difusa, compleja, heterogénea en cuanto a medios, géneros y productos pero se amalgaman con las llamadas Bellas Letras, las corrientes de pensamiento, las ciencias sociales y humanas y la llamada cultura popular. (Rivera, 1995)

En la breve historia del periodismo cultural, finalmente ya se le reconoce un lugar en los periódicos, en forma de suplementos, páginas o secciones. Quienes han ejercido y estudiado dicho periodismo han encontrado cierta "normatividad", lo que determina qué textos de la vasta producción son los idóneos para ser leídos, analizados y criticados. Asimismo, la orientación se encamina a recomendar qué tipo de espectáculos (cine, teatro, exposiciones) hay que ver.

No obstante, al periodismo actual, se nutre también de elementos de la literatura para mostrar un estilo más personal, sin descuido de informar y orientar. Por otro lado, Francisco J. Hombravella, (2) señala:

"De la literatura -como ocurre con tantas actividades humanas- no se ha encontrado una definición convincente y universalmente válida. Actividad tan antigua y viva, actual siempre, en continua evolución y transformación, siempre en la frontera de nuevos intentos por hallar inéditos caminos y formas de expresión, plantea numerosos problemas a los estudiosos que se afanan en dar con su sentido y en ordenar y clasificar, es decir, distinguir, sus múltiples manifestaciones. Creación humana y espejo del hombre y de su mundo, testigo de la historia bajo ropaje estético, su interpretación implica la necesidad de situarla en el complejo marco histórico- social que constituye la base de todo producto humano". (Hombravella, 1973: 9) 
Bajo esta precisión de conceptos, desde nuestro punto de vista, las relaciones diacrónicas y sincrónicas entre la cultura literaria y la cultura periodística describen un objeto de conocimiento que debe ser abordado desde una perspectiva interdisciplinaria, puesto que es un ámbito donde concurren las ciencias sociales, los medios de comunicación y el arte, así como en el caso particular que aquí se aborda, la literatura.

Ambos, Periodismo y Literatura, comparten el hecho de ser disciplinas humanísticas, con su propio pasado, pero de una rica actualidad y que van a la par con el cambio, por lo que están en continua evolución y transformación, y en su camino nos descubren los límites entre nuevas formas de expresión, llámese nuevo periodismo, periodismo narrativo, etc. Tanto uno como la otra, dan testimonio del acontecer histórico del hombre, aunque con una vestimenta literaria. Aquí entrarían el uso de la estilística (uso de la imagen, la metáfora, tropos, etc.)

También comparten la misma materia prima: el lenguaje. Una buena crónica y un texto literario tienen muchas cosas en común, entre otras, convencer desde las primeras líneas.

Estamos de acuerdo con Julio César Goyes Narváez (3), cuando señala: "Si el mundo del periodismo fue en sus orígenes la literatura, hoy muchos escritores intentan encontrar su estilo en el periodismo."

De ahí que de esa unión podamos considerar la literatura y al periodismo como textos que tienen mucho que compartir.

En cuanto al producto de la literatura o del periodismo, desde siempre han existido los mensajes. Una "clave" que alguien quería que otros supiesen. Un "conocimiento" que algunos querían saber. En la mitología griega ya encontramos en Hermes a un incipiente periodista. Hermes, llamado Mercurio por los romanos, era el dios encargado de la comunicación entre los dioses del Olimpo y también el vínculo entre ellos y la humanidad. También en la antigüedad existían los corresponsales como Homero, el mítico rapsoda ciego que cantó las peripecias de Ulises en La llíada y La Odisea.

En estos ejemplos es difícil separar la literatura de lo periodístico, aunque ciertamente pesa más lo literario. Diríamos que se trata de la relación marcada por la retórica.

Durante el siglo pasado, grandes escritores convirtieron el periodismo en género literario. En la prensa norteamericana destacan Tom Wolfe, Truman Capote, Graham Greene o Hemingway, donde la fuerza de su estilo predominó. Del lado de la lengua española, destacan Gabriel García Márquez, Mario Vargas Llosa, Carlos Monsiváis, Elena Poniatovska, y un gran antecesor, Leopoldo Alas, Clarín. Y si volteamos aún más hacia el pasado tenemos figuras como José Martí, Rubén Darío, Joaquín Fernández de Lizardi, Mariano José Larra, entre muchos otros.

Asentaríamos que se ha mantenido una especie de amor filial, donde ubicaríamos las aportaciones que el periodismo ha hecho a la literatura y en particular, al escritor: una disciplina para trabajar e imponerse fechas para terminar sus textos, ya que en el periodismo la escritura va al ritmo implacable del reloj. 
También el periodismo enseña a escribir en cualquier parte y en condiciones incluso extremas. Es así como este oficio le da herramientas al escritor para afinar su labor, sobre todo al novelista, porque debe escribir hasta el final de la página y una después de otra, como hace Arturo Pérez Revete.

Además de ser el periodismo una verdadera pasión, es un modo digno para un escritor de ganarse la vida, pues sabido es que las regalías de novelas, cuentos y poemas raras veces alcanzan para sostener las necesidades básicas de un creador, sobre todo cuando no ha reunido a un grupo comercialmente importante de lectores en torno a su obra.

Según el periodista argentino Tomás Eloy Martínez, el periodista no es un agente pasivo que observa la realidad y la comunica; no es una "mera polea de transmisión entre las fuentes y el lector" sino, ante todo, es el vocero que observa y describe la realidad, pero también es capaz de reconocer las emociones y las tensiones de la vida, entender el sentido de tantos por qué, para qué y cómo de las cosas.

Un gran ícono de la fusión entre periodismo y literatura es Truman Capote, autor de la novela "A sangre fría", quien fue el primero en romper, de manera estilística, lo cual es decir conscientemente, las fronteras entre la ficción y la realidad, entre el reportaje y la novela. Después de la publicación de la novela referida, un grupo de jóvenes periodistas estadounidenses comenzaron a aplicar en sus trabajos recursos narrativos identificados con la literatura de ficción, con el propósito de darle a los textos periodísticos una calidad estilística y narrativa que antes se perdía con las exigencias del modelo objetivo del periodismo norteamericano.

Por su parte, María Jesús Casals, aclara:

"Truman Capote, por ejemplo, no fue un trasgresor, es más, limpió el reportaje de truferos. Le dio una dignidad literaria y exigió, se exigió, un respeto a la verdad, al dato, a la documentación, a su distanciamiento como autor. Él mismo lo cuenta en su magnífico prólogo a Música para Camaleones (1988:7-14) y reconoce que, sin habérselo propuesto, ofreció a los clasificadores literarios un nuevo género para su colección: la novela real, aunque para no confundirla con la novela realista -nada que ver-, el nombre optó por la negación descriptiva: novela de no-ficción. Y se armó, claro. ¡Qué confusión!: ¿Literatura? ¿Periodismo? ¿Ni lo uno ni lo otro, ambas cosas? (4)

\section{2. ¿Cómo es que se dan las relaciones entre periodismo y literatura?}

Como ya hemos mencionado, es una relación fronteriza, donde el periodismo ha considerado al lector como un receptor activo, y no pasivo, de la historia. Lo deseable es atrapar su atención, contra el sopor de leer en los diarios textos fragmentados y carentes de significado. De ahí que los nuevos periodistas, como los ya mencionado Capote y Wolfe jugaran tanto con la mezcla de géneros o las voces narrativas o los artificios en sus textos. 
Ante todo, se busca traspasar los límites convencionales del periodismo. Mostrar en la prensa la vida íntima o emocional de los protagonistas, algo que hasta entonces sólo se ha encontrado en las novelas o en los cuentos. Un tipo de periodismo que se puede leer igual que una novela; o donde un artículo se puede transformar en cuento, o un reportaje tener una dimensión estética, cerca de la novela. Técnicamente se puede recurrir a los artificios literarios, que los hay y muy variados, pero, sobre todo, se busca un periodismo que se involucre más, que sea más emotivo y más personal. Es ver el periodismo con otra actitud.

Tanto el periodismo como la literatura son disciplinas con discursos de pensamiento y discursos verbales, aunque en uno predomine lo factual y en la otra la ficción. No obstante, en la actualidad las fronteras son cada vez menos definidas, ya que notamos realidad y ficción, tanto en el relato periodístico, como en el literario. De cierta manera, la producción literaria y periodística buscan contarle al lector lo que le pasó, lo que está sintiendo y pensando el personaje/autor en un lugar determinado; además el autor-periodista habla por el lector cuando denuncia y critica.

\section{Pensamiento dianoético y pensamiento noético}

Cuando hablamos de discursos de pensamiento, encontramos que en el lenguaje periodístico predomina el pensamiento dianoético o discursivo.

"Se basa en el razonamiento y permite llegar a una verdad por deducirse ella de proposiciones aceptadas como ciertas. [...] El pensamiento discursivo (se incluye en el género de conocimiento que Platón denomina Ciencia, se identifica esencialmente con las matemáticas. Es el conocimiento racional basado en los signos sensibles y en 'hipótesis'; se refiere al mundo inteligible (los objetos matemáticos)" (5)

Como ejemplo, incluimos un fragmento de una nota periodística con las características mencionadas:

Crece la nomofobia o el miedo a salir sin el celular

Ansiedad, angustia, agresividad y depresión viven el $53 \%$ de los usuarios cuando olvidan el aparato en sus casas, se les acaba la batería o no tienen señal, según un estudio español

"Si usted es una de esas personas que ni bien salió de la casa se da cuenta que no lleva su teléfono celular encima y vuelve sobre sus pasos a buscarlo o comienza a sufrir una gran ansiedad por no poder hacerlo, es posible que sufra de nomofobia.

El término proviene de la expresión en inglés 'no-mobile' (sin teléfono) y sirve para explicar el miedo irracional que sienten algunos usuarios cuando no están cerca de sus teléfonos celulares. Esta conducta se clasifica dentro de las nuevas 
enfermedades que emergieron por la aparición y el uso masivo de las nuevas tecnologías.

Según un estudio realizado por expertos españoles, el 53\% de los usuarios de teléfonos celulares sufre de esta fobia, cuyos síntomas son ansiedad, inestabilidad, agresividad y dificultad para concentrarse.

Estos síntomas se presentan cuando los usuarios olvidan el celular en sus casas, cuando les queda poca batería o cuando se encuentran en un área que tiene poca cobertura o mala señal. Además, influyen los robos y extravíos, para acrecentar los momentos de angustia por la pérdida de un aparato que suele concentrar datos preciados por los usuarios, como la agenda telefónica, fotografías y cuentas de correos electrónicos.

Otro síntoma es que cuando está en un sitio donde el uso del móvil no está permitido (cine, bancos, aviones, entre otros), la persona sufre de gran estrés. Al igual que un fumador adicto, busca la manera de salir de ese lugar para revisar el teléfono. (6)

Mientras que en la literatura predomina el pensamiento noético, entendido como: "Comprensión directa, intuitiva, de los primeros principios del conocimiento Humano". (7)

Véase el siguiente fragmento del cuento Axolotl, de Julio Cortázar (8)

"Ahora sé que no hubo nada de extraño, que eso tenía que ocurrir. Cada mañana al inclinarme sobre el acuario el reconocimiento era mayor. Sufrían, cada fibra de mi cuerpo alcanzaba ese sufrimiento amordazado, esa tortura rígida en el fondo del agua. Espiaban algo, un remoto señorío aniquilado, un tiempo de libertad en que el mundo había sido de los axolotl. No era posible que una expresión tan terrible que alcanzaba a vencer la inexpresividad forzada de sus rostros de piedra, no portara un mensaje de dolor, la prueba de esa condena eterna, de ese infierno líquido que padecían. Inútilmente quería probarme que mi propia sensibilidad proyectaba en los axolotl una conciencia inexistente. Ellos y yo sabíamos. Por eso no hubo nada de extraño en lo que ocurrió. Mi cara estaba pegada al vidrio del acuario, mis ojos trataban una vez más de penetrar el misterio de esos ojos de oro sin iris y sin pupila. Veía de muy cerca la cara de un axolotl inmóvil junto al vidrio. Sin transición, sin sorpresa, vi mi cara contra el vidrio, en vez del axolotl vi mi cara contra el vidrio, la vi fuera del acuario, la vi del otro lado del vidrio. Entonces mi cara se apartó y yo comprendí.

Sólo una cosa era extraña: seguir pensando como antes, saber. Darme cuenta de eso fue en el primer momento como el horror del enterrado vivo que despierta a su destino. Afuera mi cara volvía a acercarse al vidrio, veía mi boca de labios apretados por el esfuerzo de comprender a los axolotl. Yo era un axolotl y sabía ahora instantáneamente que ninguna comprensión era posible. Él estaba fuera 
del acuario, su pensamiento era un pensamiento fuera del acuario. Conociéndolo, siendo él mismo, yo era un axolotl y estaba en mi mundo. El horror venía -lo supe en el mismo momento- de creerme prisionero en un cuerpo de axolotl, transmigrado a él con mi pensamiento de hombre, enterrado vivo en un axolotl, condenado a moverme lúcidamente entre criaturas insensibles. Pero aquello cesó cuando una pata vino a rozarme la cara, cuando moviéndome apenas a un lado vi a un axolotl junto a mí que me miraba, y supe que también él sabía, sin comunicación posible pero tan claramente. O yo estaba también en él, o todos nosotros pensábamos como un hombre, incapaces de expresión, limitados al resplandor dorado de nuestros ojos que miraban la cara del hombre pegada al acuario.

Él volvió muchas veces, pero viene menos ahora. Pasa semanas sin asomarse. Ayer lo vi, me miró largo rato y se fue bruscamente. Me pareció que no se interesaba tanto por nosotros, que obedecía a una costumbre. Como lo único que hago es pensar, pude pensar mucho en él. Se me ocurre que al principio continuamos comunicados, que él se sentía más que nunca unido al misterio que lo obsesionaba. Pero los puentes están cortados entre él y yo porque lo que era su obsesión es ahora un axolotl, ajeno a su vida de hombre. Creo que al principio yo era capaz de volver en cierto modo a él -ah, sólo en cierto modo-, y mantener alerta su deseo de conocernos mejor. Ahora soy definitivamente un axolotl, y si pienso como un hombre es sólo porque todo axolotl piensa como un hombre dentro de su imagen de piedra rosa. Me parece que de todo esto alcancé a comunicarle algo en los primeros días, cuando yo era todavía él. Y en esta soledad final, a la que él ya no vuelve, me consuela pensar que acaso va a escribir sobre nosotros, creyendo imaginar un cuento va a escribir todo esto sobre los axolotl."

Para comprender más las relaciones entre periodismo y literatura, tenemos más sustento teórico que nos permita entender la discursividad de uno y otro género, a través del pensamiento analítico y el pensamiento intuitivo (9), el primero se desarrolla dando un paso cada vez. Los pasos son explícitos y por sistema se reportan apropiadamente por el pensador-investigador-periodista-escritor a otro individuo. Este pensamiento avanza con una conciencia relativamente amplia de la información y de las operaciones involucradas. Abarca un razonamiento cuidadoso y deductivo, usa las matemáticas o la lógica, mediante un plan, o bien puede comprender un proceso de deducción y experimentación, utilizando principios de diseño de investigación y análisis estadístico. Lo anterior describe fielmente el oficio del periodista.

Diferentes, pero a la vez, complementario con el pensamiento analítico, el pensamiento intuitivo no avanza por pasos cuidadosos y bien definidos, sino que tiende a incluir maniobras basadas aparentemente en una percepción implícita de la totalidad del problema. El pensador-investigador-periodista-escritor llega a una respuesta que, tal vez pueda ser correcta o incorrecta, o quizás con muy poca o ninguna conciencia del proceso mediante el 
cual llegó a ella y rara vez puede proporcionar una relación adecuada de la manera en que obtuvo su respuesta, y suele no darse cuenta de, exactamente, a cuáles aspectos de la situación problemática estaba respondiendo. Se basa en una familiaridad, lo que hace posible para el pensador "brincar", omitiendo pasos y empleando vías cortas. El pensamiento intuitivo produce rápidamente hipótesis. Es lo que se conoce como "corazonada".

\section{Dos tipos de imaginación}

Para Kant existen dos tipos de imaginación: imaginación reproductora e imaginación productora (10). La primera se da en el entendimiento y subsiste sin necesidad de presentarse un objeto frente a los sentidos. Umberto Eco la llama imagen evocadora porque estamos en la delineación de mundos posibles. (11)

Este es el tipo de imaginación que predomina en el periodismo ya que evoca imágenes, algunas de las cuales se han hecho presentes al sujeto a través de intuiciones sensibles, mientras que otras sólo por medio de un esfuerzo del entendimiento de reproducir lo que en cierta forma ya fue conocido. Como se muestra en el siguiente ejemplo:

Entregará Congreso Medalla de Honor Víctor Hugo Rascón Banda el jueves 22

Noticias - Chihuahua

Escrito por Sergio Armando Ramírez Ruiz

Martes 20 de septiembre de 2011 12:27

Al ganador Mario Arras, además anunció sesión solemne para recibir al gobernador del estado César Duarte en lo que será su primer informe de gobierno el 1 을 de Octubre

Benjamín Palacios Perches, secretario de Servicios Parlamentarios y Vinculación del Congreso del estado, acompañado por el titular del área de Comunicación Social, Edgar Itamar Rivera, anunciaron las fechas de dos importantes sesiones solemnes que se desarrollarán en breve en el recinto de la legislatura, la primera será para entregar la medalla "Víctor Hugo Rascón Banda" a Mario Arras, que se efectuará el jueves 22 a las 10 de la mañana. Mientras que el primero de Octubre a las 9 de la mañana será recibido el gobernador del estado César Duarte, también en sesión solemne por motivo de su primer informe de gobierno.

Palacios Perches mencionó que todo está listo para entregar la medalla al ganador, contando con la presencia de todos los legisladores de los partidos políticos quienes en comisión entregará la presea a Mario Arras, que se ha distinguido a lo largo de este 2011 por su destacada participación en la cultura.

Así mismo corroboró que "el sábado primero de octubre el gobernador acudirá al recinto legislativo por ahí de las 9 de la mañana para entregar a los legisladores 
el compendio de su primer informe de gobierno, ofrecer unas palabras y salir rumbo al Teatro de los Héroes donde rendirá un informe a la sociedad". (12)

Por otro lado, tenemos la imaginación como figuración (Eco prefiere llamarla así porque este figurar es para comprender y comprender figurando es crucial en el sistema kantiano: se demuestra esencial tanto para fundar trascendentalmente los conceptos empírico, como para permitir juicios perceptivos -implícitos y no verbalizados- como esta piedra.(13) o como la capacidad de figurar, es decir, en términos kantianos: synthesis speciosa (imaginación productora). Bajo este concepto, Kant hace referencia a la capacidad imaginativa, o más bien, figurativa, de pensar en el objeto lo que bajo un concepto puro es intuido, es decir, formarse una idea clara de lo que es un objeto bajo una categoría determinada (14). Este tipo de imaginación es el que caracteriza a la literatura. Como en el siguiente ejemplo:

\section{"Rencorante}

Por su forma, se confunde con el carbón. Es igual de negro, pero más áspero y rugoso y también te deja una mancha difícil de quitar. Es tan grande como lo quieras ver o sentir. Ten cuidado porque se personaliza. Si lo atrapas, se te adhiere y formas parte de su propio ser. Desde ese momento serás una persona diferente, con mirada diferente, con los latidos del corazón, incluso el corazón mismo, diferentes: Tu órgano cordial se convierte en una masa gelatinosa de color putrefacto. El aroma tú no lo percibes porque ya te acostumbraste a él. Pero los que te rodean se alejan de ti pues hueles a vómito. Cuando saludas, tu mano aprieta y hace daño, el rencor te da una fuerza fuera de lo normal. Cuando hablas, tu voz es murmurante, resbalosa, no terminas las palabras ni las frases y cada vez que te preguntan, crece en tu interior el rencorante. Es el que te enemista, el que te hace odiar las cosas perfectas, armoniosas, bien hechas. Ni se te ocurra mirarte en el espejo porque ya nunca se saldrá de ti. Mejor busca el reflejo de la luna en cualquier charco y póstrate, mírate, y grita desde el fondo de tu alma para que se salga ese rencor que tienes ya enredado en tus vísceras. No te asustes si sientes que por la boca abierta se te sale una gasa negra como telaraña: es tu rencorante que se te estaba extendiendo como un cáncer." (15)

\section{Conclusiones}

Al revisar textos periodísticos y textos literarios, y analizando minuciosamente uno y otro, con las lentes arriba mencionadas, encontramos que de manera tradicional, cotidiana, ambas son actividades netamente humanas que buscan al lector para informar, orientar y deleitar, mediante un tipo de lenguaje literario que registra la historia o con buenas dosis de subjetividad .

En la parte de los procesos mentales, el tipo de pensamiento que se da en el periodismo es el dianoético, mientras que en la literatura se da el noético; el pensamiento analítico es propio del proceso intelectual realizado de manera diaria por el periodista; mientras que el 
pensamiento intuitivo se da preferentemente y más en los textos literarios; la imaginación reproductora o re-productiva es la que se hace presente en el quehacer del periodista, mientras que la imaginación productora o figurativa se manifiesta en la literatura. No obstante, al momento de la fusión, de la cual trata este trabajo, se complementan las dicotomías, logrando un balance discursivo que permite el disfrute al lector, objeto último del periodismo y de la literatura.

El ejercicio del periodismo literario, está rompiendo esquemas en el mundo periodístico, y ya se identifica en el periodismo metropolitano, pero al parecer, como muchos fenómenos culturales, se ha tardado en ser practicado, usado y reconocido en el ámbito regional.

La noticia ha dejado de ser objetiva para volverse individual, pero siempre como una voz a través de la cual se puede pensar la realidad, reconocer las emociones y las tensiones secretas con el deslumbramiento de quien las está viviendo por primera vez.

La gran propuesta del periodismo es

"descubrir, donde antes había solo un hecho, al ser humano que está detrás de ese hecho, a la persona de carne y hueso afectada por los vientos de la realidad... Allí donde el documento parece instalar una certeza, el periodismo instala siempre una pregunta. Preguntar, indagar, conocer, dudar, confirmar cien veces antes de informar: esos son los verbos capitales de la profesión más arriesgada y más apasionante del mundo". (16)

La cercanía del periodismo cultural con la literatura queda patente en el pensamiento del periodista Tomás Eloy Martínez cuando apunta que entre periodismo y literatura no hay distancias:

"Esa relación se divide cuando ocurre el encuentro con el lector, pero el que produce un texto es siempre un escritor y su producto es literatura. Lo que ocurre es que hay un compromiso distinto frente al texto; en el periodismo hay fidelidad con la verdad, y en la literatura la fidelidad es con el autor mismo: el escritor piensa en él y no en el lector". (17)

\section{Bibliografía}

Acosta Montoro, José. (1973): Periodismo y literatura. Madrid, Guadarrama. 2 vols.

Alonso Pedraz, Martín. (1975) Ciencia del lenguaje y arte del estilo. Tomo I. Aguilar S.A., Madrid.

Bernal Rodríguez, Manuel y otros (1997): Realidad y ficción en el discurso periodístico. Sevilla, Padilla.

Bruner, Jerome. El Proceso de la Educación. ("The Process of Education”). México D.F. Unión Tipográfica 
DICCIONARIO DE FILOSOFÍA Breve definición de los términos filosóficosfundamentales" http://www.e-torredebabel.com/DiccionarioFilosofia/Diccionario-Filosofico-P02.htm

Cortazar, Julio: Ciudad Selva, Biblioteca Digital. (actualizado al 10/10/2011) http://www.ciudadseva.com/textos/cuentos/esp/cortazar/axolotl.htm

Eco, Umberto.(1999) Kant y el ornitorrinco. Editorial Lumen S.A. Barcelona, 1999.

Editorial Hispano- Americana (1968) (Colecciones Manuales UTEHA. Serie Educación. Número 17).

García Pérez, José Antonio. (2009) Textiario. Cuentos para apaciguar la bestia que llevamos dentro. Colección Flor de Arena No. 74.Litográfica Voz, S.A. de C.V. UACH-SPACUACH. Chihuahuha, México.

Gamboa, Santiago. Santiago Gamboa 29/11/2007 El País.com Santiago Gamboa es corresponsal colombiano en Europa desde hace 20 años y autor de libros como Perder es cuestión de método y El síndrome de Ulises.

Kant, Immanuel. Crítica de la Razón Pura: (2006) Ed. Digital basada en el de la Editorial de Madrid Librería General de Víctor Suárez, 1928. Obtenido desde www.cervantesvirtual.com

Lepe Carrión, Patricio (2009): La construcción esquemática en Kant y la imaginación como facultad determinante a priori de la sensibilidad. A Parte rei No. 61.

Salvat, Manuel. (1973) Qué es la literatura. Biblioteca Salvat de Grandes temas, Salvat Editores de México S.A., México.

Wiñazki, Miguer - Campa, Riccardo (1995): Periodismo: ficción y realidad. Buenos Aires, Biblo.

\section{Notas:}

1) El subrayado es nuestro.

2) Franciso J. Hombravella firma el capítulo: El concepto de literatura y la narrativa, Pag. 9, en el texto: Qué es la literatura. Salvat Editores, de México S.A., México 1973

3) A propósito de periodismo y literatura. Julio César Goyes Narváez. CV Autor. Profesor del Instituto de Estudios en Comunicación y Cultura (leco), de la Universidad Nacional de Colombia.

4) Colaboración Especial de: Verónica Muñoz Ayala, Licenciatura en Comunicación FES Acatlán, basado en www.mexicanadecomunicación.com.mx "Letras del Nuevo Periodismo", colaboración de Maricarmen Fernández Chapou de El Financiero. "Nuevo periodismo", Tom Wolfe, 1975. México, 2006.

5) DICCIONARIO DE FILOSOFÍA Breve definición de los términos filosóficos fundamentales.

6) http://www.e-torredebabel.com/DiccionarioFilosofia/Diccionario-Filosofico-P02.htm

7) Nota tomada de La Nación. Com. 21 de septiembre de 2011 
8) http://www.lanacion.com.ar/1408061-crece-la-nomofobia-o-el-miedo-a-salir-sin-el-celular

9) (lbid.)

10) http://www.e-torredebabel.com/DiccionarioFilosofia/Diccionario-Filosofico-P02.htm

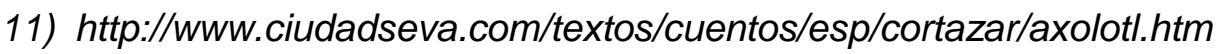

12) Bruner, Jerome. "El Proceso de la Educación". ("The Process of Education”). México D.F. Unión Tipográfica Editorial Hispano- Americana (Colecciones Manuales UTEHA. Serie Educación. Número 17). 1968. (Pags. 89 a 93)

13) Kant, Immanuel. Crítica de la Razón Pura. Ed. Digital basada en el de la Editorial de Madrid Librería General de Víctor Suárez, 1928. Obtenido desde www.cervantesvirtual.com, el 01 de dic. De 2006.

14) Eco, Umberto. Kant y el ornitorrinco. Editorial Lumen S.A. Barcelona, 1999.)

15) http://diario.devenir.com.mx/index.php?option=com_content\&view=article\&id=8564:entregaracongreso-medalla-de-honor-victor-hugo-rascon-banda-el-jueves-

22\&catid=36: chihuahua\&/temid $=56$

16) Eco, Op. Cit.

17) Lepe Carrión, Patricio. La construcción esquemática en Kant y la imaginación como facultad determinante a priori de la sensibilidad. A Parte rei No. 61. Enero 2009. Cap. II, Pág. 3

18) García Pérez, José Antonio. (2009) Textiario. Cuentos para apaciguar la bestia que llevamos dentro. Colección Flor de Arena No. 74.Litográfica Voz, S.A. de C.V. UACH-SPACUACH. Chihuahuha, México. Pág. 111

19) http://www.tercera.cl/diario/1999/03/19/19.43.3a.CUL.ELOY.html

20) Ibidem

\section{Forma de citar este artículo en bibliografías}

CORTÉS MONTALVO, J. y GARCÍA PÉREZ, J. A. (2012): "Relaciones entre periodismo y literatura: fusión sin confusión", en Revista PANGEA, 3, páginas 38 a 50. Red Académica Iberoamericana de Comunicación. Recuperado el de de 2 de: http://revistapangea.org 